\title{
Thermal Analyses of the Los Angeles Smog Aerosol
}

\author{
R. B. HUSAR ${ }^{1}$ AND W. R. SHU \\ W. M. Keck Laboratories of Environmental Heallh Engineering, California Institute of Technology, Pasadena 91109
}

(Manuscript received 20 February 1975, in revised form 25 July 1975)

\section{ABSTRACT}

It has been shown by earlier studies on the formation of the Los Angeles smog aerosol, that a significant fraction $\mathrm{cf}$ the particulate matter in the visible size range is made by secondary gas-particle conversion processes, and that it consists mainly of liquid matter. In this study the volatility was studied quantitatively by heating the smog aerosol up to $250^{\circ} \mathrm{C}$ and simultaneously measuring the scattering coeficient using a nephelometer and the change of size distribution by an optical counter. The thermal analyses revealed that $50-80 \%$ of the submicron aerosol mass is volatile at $220^{\circ} \mathrm{C}$. Inspection of the shapes of thermo-nephelograms $\left(b_{\text {seat }}\right.$ vs temperature) also revealed that photochemically formed aerosols have distinctly different thermo-nephelograms than those obtained on humid "hazy" days. Thus it is suggested that thermal analyses may at least in some instances provide the means of on-line monitoring the origin of the ambient aerosol.

\section{Introduction}

The physical and chemical properties of the Los Angeles smog have intrigued researchers since the early 1950's when it was discovered that the smog formation is largely due to the photochemical reaction products of automobile exhaust gases (Haagen-Smit, 1952). Early studies conducted by the Stanford Research Institute (Cadle et al., 1950; Rubin, 1952) revealed that most of the smog aerosol mass is in the form of liquid droplets. These early studies also indicated that the smog aerosol is largely composed of organic matter (Mader et al., 1954). In the past five years, the smog aerosol again received a great deal of attention (Whitby et al., 1972; Hidy, 1972) and the role of physical mechanisms and processes (Husar et al., 1972) as well as the contributions of different sources to the smog aerosol content (Friedlander, 1973) were assessed quantitatively. In a later analysis, it was even found possible to synthesize the smog aerosol size spectrum from the spectral contributions of individual sources such as the automobile (primary and secondary), industrial, marine aerosol, etc. (Heisler et al., 1973; Gartrell and Friedlander, 1975).

In performing such aerosol balance calculations, however, there remains a major uncertainty concerning the content of water and other volatile matter such as organics (Commins and Lawther, 1958) in the ambient aerosol due to inadequate data. The present study was thus initiated with the purpose to

\footnotetext{
1 Present affiliation: Air Pollution Research Laboratory, Department of Mechanical Engineering, Washington University, St. Louis, Missouri 63130.
}

elucidate the aerosol volatile fraction and, if possible, derive quantitative data on the volatility, i.e., under certain conditions (mainly temperature), how much of the ambient aerosol is driven from the aerosol into the gas phase. For this purpose we adapted a tool of analytical chemistry referred to as thermal analysis (TA). Results of controlled thermal exposure and analyses of urban aerosols were first reported by Goetz et al. (1961). They showed that deposited marine aerosol changes insignificantly after exposure to $80^{\circ} \mathrm{C}$ air, i.e., it is not volatile at that temperature. On the other hand, about $80 \%$ of the Los Angeles smog aerosol in the size range below $0.5 \mu \mathrm{m}$ volatilized at $80^{\circ} \mathrm{C}$. They found that at this temperature, the subrange between 0.5 and $1.3 \mu \mathrm{m}$ did not change substantially.

Thermal analysis, i.e., the analysis of physical or chemical properties of a substance as a function of temperature, has been used by other investigators to study the behavior of natural aerosols (Dinger et al., 1970; Pueschel et al., 1973). In the present work, the light scattering component $(0.2-1.0 \mu \mathrm{m})$ of the Los Angeles aerosol was thermally analyzed using two in situ detection techniques, nephelometry and optical aerosol counting. Additional information on the aerosol morphology was gained by impaction and subsequent electron microscopic analyses of heated and unheated samples.

\section{Experimental setup \\ a. Description of the equipment}

The experimental setup used in this study is shown schematically in Fig. 1. It consists of three major 


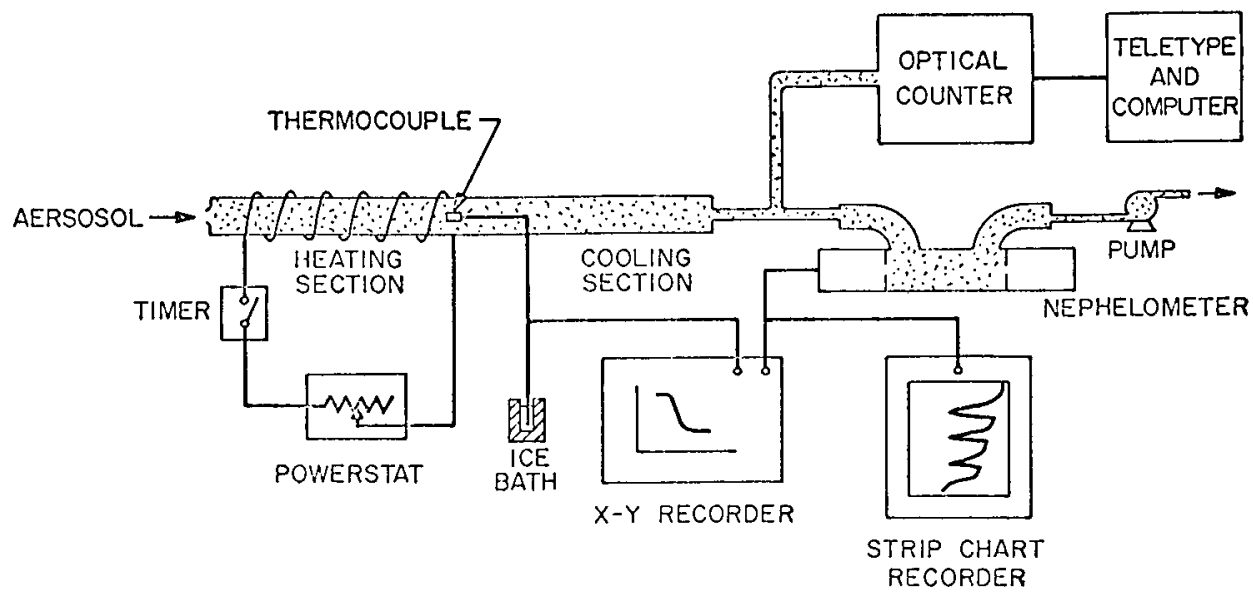

Fig. 1. Schematics of the experimental setup for the aerosol thermal analyses.

components, the heater, the aerosol sensor (nephelometer or optical counter), and data recorders. Aerosol is sampled through a pyrex glass heating pipe before it enters the nephelometer. The fin-like obstructions extending from the inner wall to the center of the pyrex pipe insure the mixing and uniform heating of the aerosol samples. The first section of the pipe is wrapped with a heating strip, and the aerosol passing through this section can be heated up to $300^{\circ} \mathrm{C}$. The rate of heating is controlled by the power input and the air flow rate. A timer turns the power on or off, and hence it controls the heating time. The average aerosol flow rate through the heater was set at $500 \mathrm{~cm}^{3} \mathrm{~s}^{-1}$. and the corresponding aerosol residence time in the heater was $0.24 \mathrm{~s}$. After heating, the aerosol passes through the other half of the pyrex pipe and cools down to about $30^{\circ} \mathrm{C}$, and then enters the nephelometer.

The temperature of the heated aerosol is measured by a Fe-Co thermocouple of which one end is placed in a teflon radiation shield and rested at the end of the heating section of the pipe. Hence it measures the maximum temperature to which the aerosol has been heated. The other end of the thermocouple is immersed in an ice bath as the reference temperature.

Aerosol samples were monitored both by a Climet optical counter and by the nephelometer. The optical counter measures the aerosol size distribution in the diameter range 0.25 to $2.0 \mu \mathrm{m}$ (Husar, 1974). The output signal of the counter is pulse-height analyzed by a multichannel analyzer and the size spectrum data are processed and plotted by an IBM $360 / 65$ computer through a remote terminal. The nephelometer (Ahlquist and Charlson, 1967) measures the total light scattering coefficient $b_{\text {scat }}$. Its output signal is sent into two recording units: a continuous strip-chart recorder which records the time history of the total light scattering, during heating and cooling periods, and an X-Y recorder which plots the total light scattering coefficient vs temperature.

\section{b. Calibration of the instruments}

The calibration procedures of the nephelometer are described in the manufacturer's manual (Meteorology Research, Inc.). An absolute calibration was made using air and Freon 12 as two reference data points according to the manual. A zero air calibration was also made by inserting a total filter at the entrance of the nephelometer, and the zero air reading was at $0.3 \times 10^{-4} \mathrm{~m}^{-1}$. Hence for all the nephelometer data this amount of light scattering was deducted to obtain the light scattering contributed by the aerosol.

The possible loss of the aerosol particles in passing through the heating tube is checked by bypassing the heating system and comparing the readings of the nephelometer with and without the heating tube. For atmospheric aerosol, no observable loss of $b_{\text {scat }}$ in the heating system was found. Further data on the potential aerosol loss due to thermal diffusion upon heating will be discussed later.

The time response of the heating and cooling system was also studied. Based on a number of temperature vs time curves, the settings of the powerstat and the timer were chosen such that the maximum temperature of the aerosol after heating was about $250^{\circ} \mathrm{C}$ and the heating-and-cooling cycle took less than $30 \mathrm{~min}$. It was observed at $250^{\circ} \mathrm{C}$, for most of the substances, that the total light scattering approached an almost constant value. The $30 \mathrm{~min}$ cycle time was adapted because atmospheric aerosol conditions tended to change rapidly and it is desirable to have the shortest possible time resolution.

The calibration of the optical counter was performed according to the procedures described by Husar (1974).

Before considering the thermal behavior of the atmospheric aerosol it is instructive to give a short consideration to the thermal behavior of a few known substances. 


\section{Thermo-nephelograms of known aerosols}

As noted before, aerosol particles of volatile substances will reduce their masses by evaporation or decomposition upon heating, and hence reduce their total light scattering. A plot of the total light scattering $b_{\text {seat }}$ vs the temperature $T$ of an aerosol sample reveals the thermal behavior of the aerosol; such a plot will hereafter be called a thermo-nephelogram (TNG). Because of their different thermodynamic properties, aerosols of various substances will exhibit their own particular TNG's. Hence by comparing the TNG's of aerosol of unknown composition with those of aerosols of known substances one might be able to tell the possible composition of the unknown aerosols.

Experiments were performed using $\mathrm{NaCl}$, polystyrene latex, cigarette smoke, and di-octyl phthalate (DOP) aerosols. These aerosols, except cigarette smoke, were prepared by a neublizer filled with either water or alcohol solutions of the particular substances. The median diameter of the nebulizer droplets was about $8 \mu \mathrm{m}$ and using solutions of 0.1 weight percent the resulting dry particles were of submicron size $(\sim 0.8 \mu \mathrm{m})$.

The results of the TNG experiments on known substances are shown in Figs. 2 and 3. First of all, it was observed that the heating of the non-volatile polystyrene latex aerosol has minimal effect on its light scattering. The $10 \%$ decrease of $b_{\text {seat }}$ observed at the end of heating process may partly be attributed to the loss of the particles in the system. Sodium chloride has a boiling point of $1413^{\circ} \mathrm{C}$ and it is considered non-volatile. Accordingly, it shows almost no decrease in $b_{\text {scat }}$ upon heating. The sudden decrease in the beginning of the heating process is attributed to the loss of hydrated water in the $\mathrm{NaCl}$ crystal.

The TNG's of volatile substances are considerably different from those observed above. Cigarette smoke, for instance, responds to the heating immediately and its $b_{\mathrm{gcat}}$ decays almost linearly with increasing temperature. DOP aerosol, on the other hand, behaves

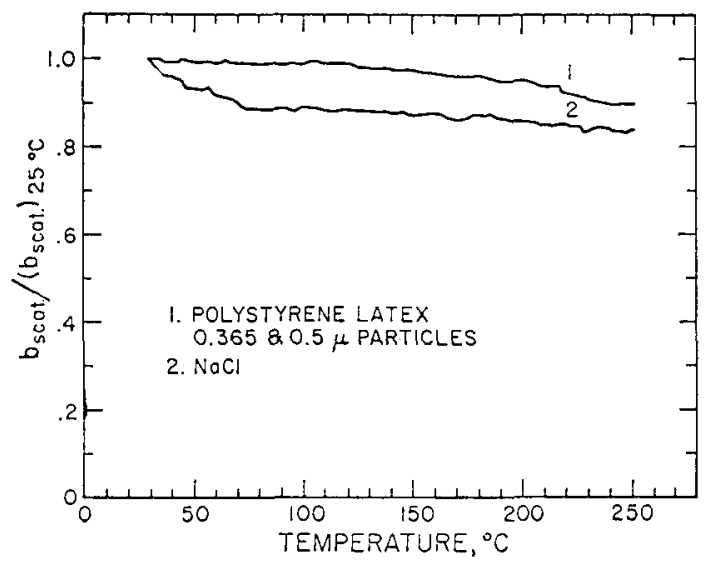

FIG. 2. Thermo-nephelograms of known solid substances.

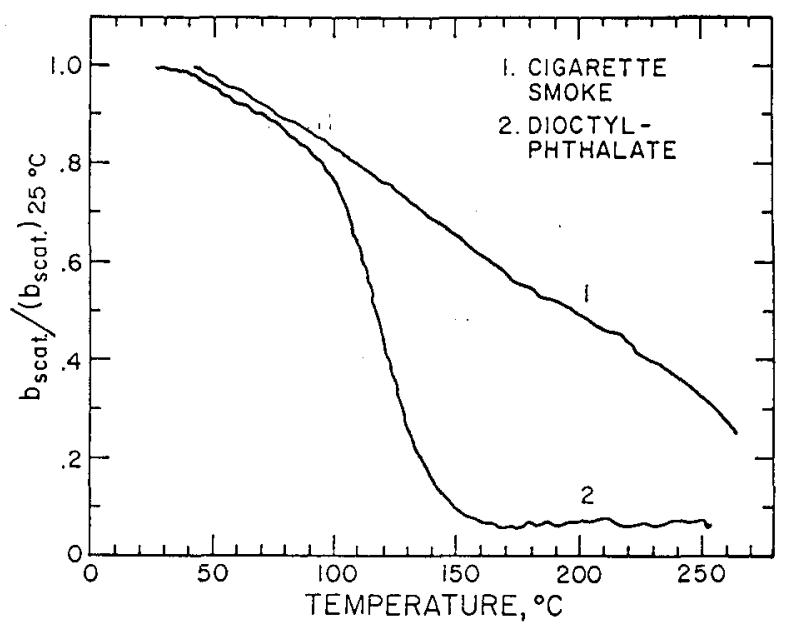

FIG. 3. Thermo-nephelograms of known volatile substances.

differently. Its $b_{\text {seat }}$ first decays slowly and at about $100^{\circ} \mathrm{C}$ it starts to drop sharply and reaches almost zero $b_{\text {scat }}$ at about $150^{\circ} \mathrm{C}$. The optical counter also showed that at this moment virtually no particles in optical range were left, so that all DOP particles have evaporated.

It is worthwhile at this point to comment that from the DOP data, we have not observed an increase of $b_{\mathrm{scat}}$ during the cooling process after heating. Hence it is concluded that there is either no recondensation after heating aerosols of low vapor pressure or the recondensing particles are in the sub-optical size range.

The sets of data shown in Figs. 2 and 3 are of considerable importance in serving as reference data for analyzing the TNG's of atmospheric aerosol. The first set of data shows that solid materials such as sea salt do not evaporate appreciably on heating. The second group of data shows that for volatile substances the total light scattering is a strong function of temperature. For some combustion products, such as cigarette smoke, $b_{\text {scat }}$ is almost a linear function of temperature, while for oil-like organic compounds the TNG shows a reverse S-shaped curve.

\section{Thermal analyses of Pasadena aerosol}

Thermal analyses of atmospheric aerosol were performed in Pasadena in the northern section of the Los Angeles basin. It is a receptor site for marine air as well as air pollutants emitted in the coastal areas and over downtown Los Angeles. The local sources are considered of minor significance to the ambient aerosol concentration in Pasadena.

Continuous thermal analyses were made for about 20 days, under a variety of meteorological conditions. Inspection of all TNG's revealed that the Pasadena aerosol exhibits two distinctly different types of thermal behavior as shown in Fig. 4. One occurred on partly cloudy, hazy days with relatively low photochemical 


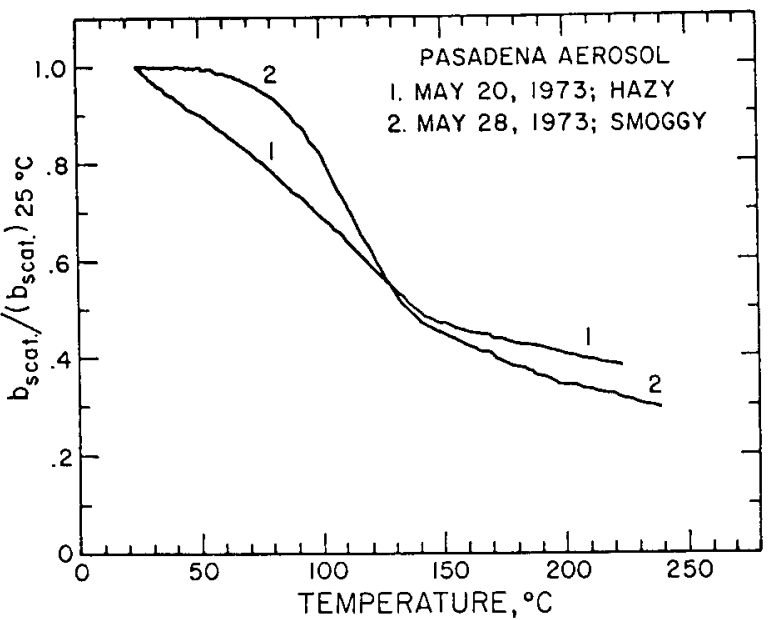

Fig. 4. Comparison of TNG's obtained on "hazy" and "smoggy" days.

activity and the other type occurred on smoggy days with high ozone, eye irritation and the typical smell of photochemical smog. On a typical smoggy day (28 May 1973) the TNG exhibits a reverse S-shape while on a typical hazy day (20 May 1973) the $b_{\text {scat }}$ decreases linearly with temperature up to $150^{\circ} \mathrm{C}$.

It has also been observed that during a given day TNG's can change within an hour's time as shown by the data given in Fig. 5. At 1140 on 9 May 1973 the TNG is of the "hazy" aerosol type, while by 1320 it turns to the reverse S-shaped TNG characteristic of "smog" aerosol.

In order to test if the changes in $b_{\text {scat }}$ with temperature are due to the loss of volatile matter and not merely due to a shift in the size distribution to outside the optical subrange, a series of aerosol size spectra were taken with the Climet optical counter. The results, given in Fig. 6, show that a loss of aerosol

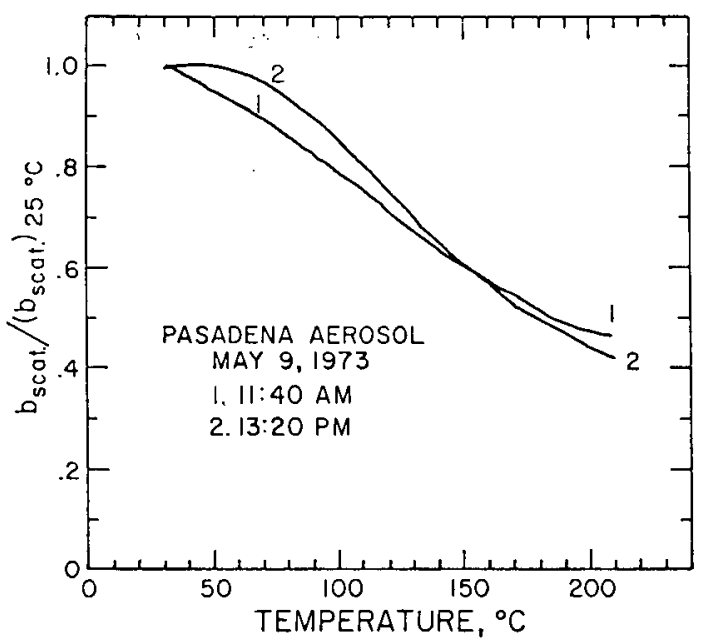

FiG. 5. Change of the TNG from "hazy" type to "smoggy" type within $100 \mathrm{~min}$ on the same day.

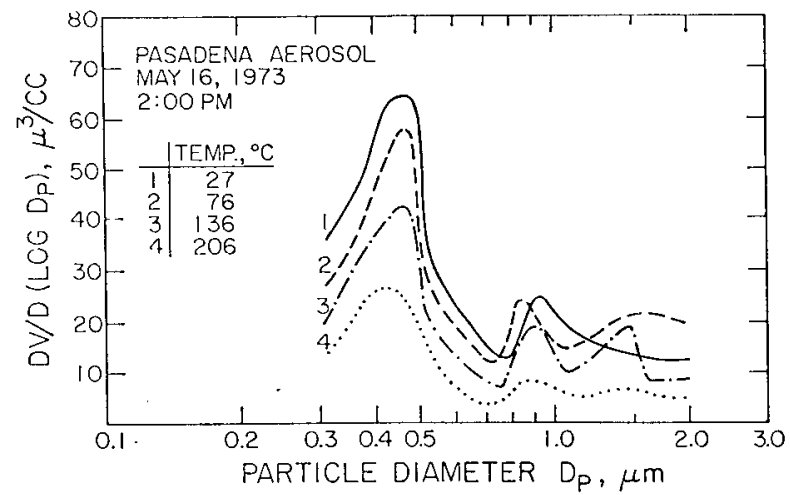

FIG. 6. Decay of the ambient Pasadena aerosol size spectrum with increasing temperature.

mass occurs at all sizes upon heating to $200^{\circ} \mathrm{C}$. In this study no attempt was made to arrive at an aerosol "loss law," i.e., the loss rate as a function of particle size, temperature and ambient humidity.

From Figs. 4 and 5 it is apparent that a substantial portion of the Los Angeles smog aerosol in the light scattering subrange $0.2-1.0 \mu \mathrm{m}$ (Ensor $e t$ al., 1972) is composed of matter which becomes volatile at about $150^{\circ} \mathrm{C}$. As we shall discuss further, the volatile fraction ranges between $50 \%$ and $80 \%$ of the total light scattering aerosol. This has been noted by earlier investigators and it is also consistent with the secondary, i.e., in situ, origin of the Los Angeles smog aerosol (e.g., Husar et al., 1972; Friedlander, 1973).

\section{Diurnal pattern of volatile fraction of Pasadena aerosol}

The diurnal pattern of aerosol volatility was studied by analyzing the strip-chart recordings of cyclically heated and cooled aerosol. We define the volatile fraction $V$ as the ratio of the $b_{\text {scat }}$ change due to heating to the $b_{\text {scat }}$ before heating:

$$
V=\frac{\left(b_{\text {scat }}\right)_{25^{\circ} \mathrm{C}}-\left(b_{\text {seat }}\right)_{250^{\circ} \mathrm{C}}}{\left(b_{\text {scat }}\right)_{25^{\circ} \mathrm{C}}} .
$$

Two sets of data, representing two weather conditions, are given in Figs. 7 and 8.

On the smoggy day 3 May 1973 the diurnal patterns of $b_{\text {seat }}$ exhibit the commonly observed increase until noon (Whitby et al., 1972) followed by a drop due to the arrival of the sea breeze. During the night, the volatile fraction is constant at about 0.5 . In the morning the volatile fraction increases and reaches 0.75 at noon. With the arrival of the sea breeze not only $b_{\text {scat }}$ but also the volatile fraction of the aerosol drops to 0.4 . The decrease in volatility is coinciding with the arrival of a new air mass, having a larger fraction of marine (sea salt) and primary emission aerosol, and a smaller fraction of volatile secondary aerosol. 


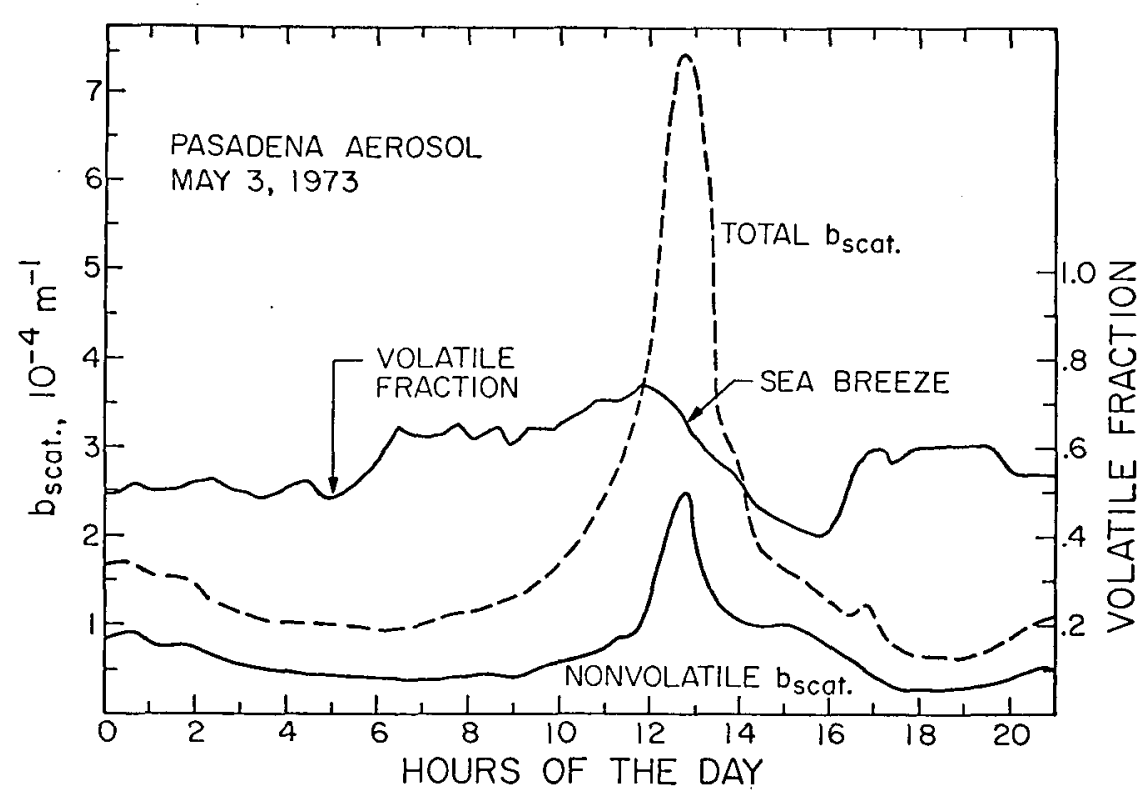

Fig. 7. Diurnal pattern of total $b_{\text {scat }}$, nonvolatile $b_{\text {scat }}$, and volatile fraction on a smoggy day.

The aerosol volatility on the hazy day (20 May 1973) is shown in Fig. 8. It differs from the smoggy day in that the volatile fraction remains at high level, 0.6 to 0.8 all day. The arrival of the sea breeze on this day made only a small change in the volatility, thus suggesting that the physicochemical properties of the haze aerosol were similar during the entire day.

\section{Electron microscopy of the ambient aerosol}

Following these findings, it appeared that the visibility-reducing aerosols have different physicochemical properties and possibly different origins depending on weather conditions. It is therefore of interest to use additional tools such as transmission electron microscopy for investigating the properties of the two types of aerosols.

\section{a. Smog aerosol}

The physiochemical properties of the Los Angeles smog aerosol have been studied extensively by the Air Pollution Foundation, and later in the 1969 Pasadena Aerosol study (Hidy, 1972). The main conclusion of these studies is that most of the smog aerosol mass is confined to the submicron range ( 0.1 to $1.0 \mu \mathrm{m}$ in diameter) and its chemical composition is dominated by sulfates, nitrates and organic matters (Gartrell and Friedlander, 1975).

An electron micrograph of the smog aerosol, impacted on an electron microscope grid by a five-stage impactor (at a cutoff size of $0.3 \mu \mathrm{m}$ ) is shown in Fig. 9a. Most of the deposited matter is made of flat residues of aerosol droplets. In Fig. 9b a smog aerosol sample is shown after it has been heated to $150^{\circ} \mathrm{C}$

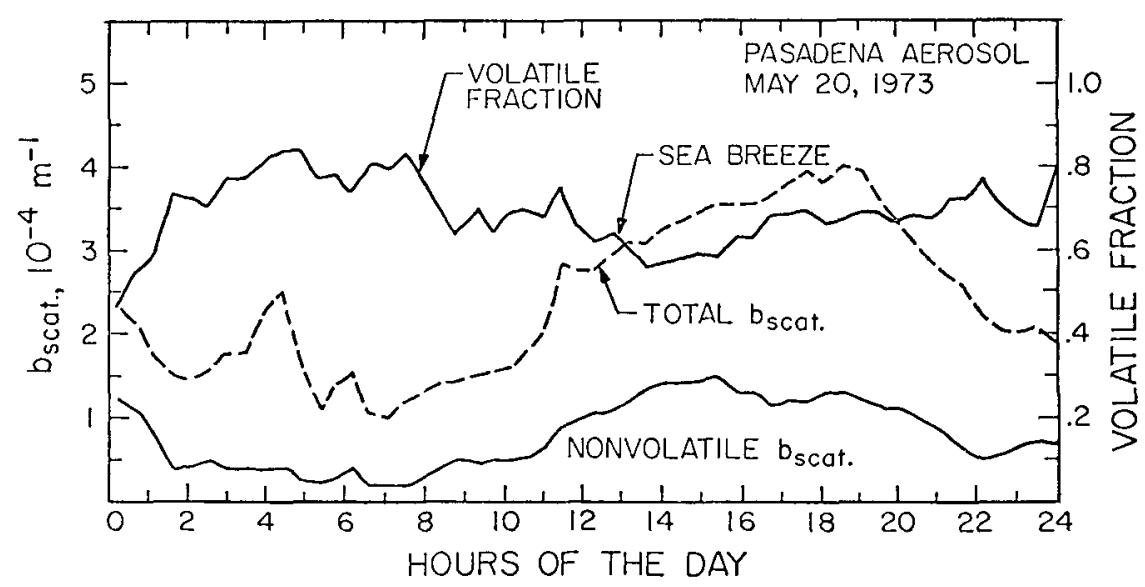

FIG. 8. Diurnal pattern of total $b_{\text {scat }}$ and nonvolatile $b_{\text {scat }}$ on a hazy day. 

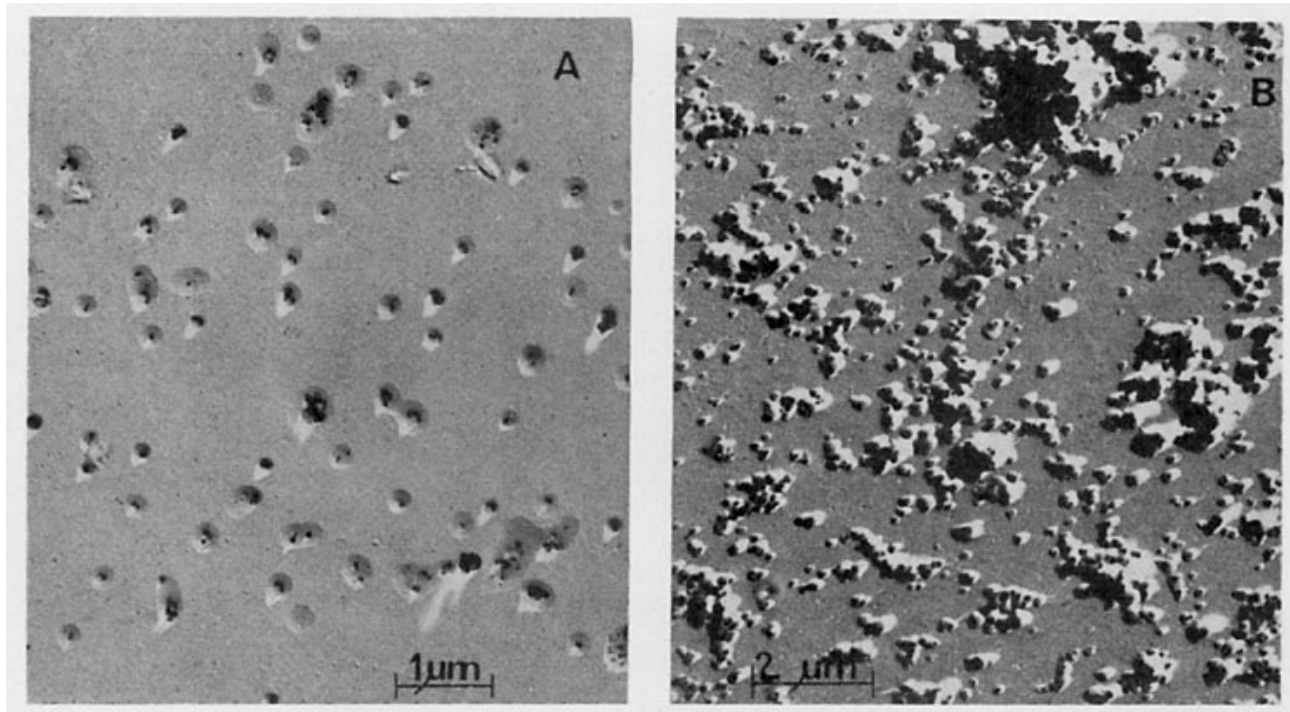

Fig. 9. Electron micrographs of Los Angeles smog aerosol samples collected on transmission electron microscope (EM) grid by a five-stage impactor at size cutoff centering $0.3 \mu \mathrm{m}$. a) Unheated smog aerosol sample consisting primarily of flat residues of droplets. b) Smog aerosol sample heated in situ and then impacted on EM grid. These particles are solid and almost spherical.

and subsequently deposited on an electron microscope grid. The morphology of these particles is drastically different in that they consist of solid spheres as shown by their circular shadows.

These observations, along with the TNG's, suggest that the smog aerosol is made of low vapor pressure liquids (possibly organic) and some solid deposits. These low vapor pressure liquids are almost nonvolatile until $100^{\circ} \mathrm{C}$. The submicron volume proportion of the liquids to the solids is about 3 as suggested by the observed volatile fraction.

\section{b. Haze aerosol}

Nuch less attention has been devoted in the past to the haze aerosol. Haze aerosol was sampled and analyzed on days that were characterized by the weather forecasts: "low clouds in the morning, hazy sunshine in the afternoon." Although the oxidant level and the lung and eye irritation is less severe on these days, the haziness or light scattering coefficient may be comparable to the "smoggy" days. The haze appears to be natural and a direct consequence of the moist marine air penetrating the Los Angeles basin.

In preparation, ${ }^{2}$ evidence is presented that the haze aerosol that persists in the afternoon is due to stabilized cloud and fog droplets by evaporationretarding monolayers. Part of this evidence is shown on the electron micrographs in Figs. 10a and 10b. The residues of deposited haze particles show peculiar wrinkles, extending from the center to the edge of a given deposit. For comparison on smoggy days (Fig. 9) the droplet residues were generally found smooth and there was no evidence for such wrinkles. The structure

${ }^{2}$ Husar, R. B., 1976. of those wrinkles is best illustrated in Fig. 10b. It indicates that these wrinkles are the manifestation of a nonvolatile coating that shrank and wrinkled after the volatile fraction of the droplet (probably water) evaporated in the vacuum of the electron microscope.

Heating and subsequent electron microscopy of haze particles also show interesting features (Fig. 10c). These particles give the appearance of a thick-walled rubber ball that folded after the air has been evacuated from its interior. Accordingly, we envision the following processes occurring during the heating of the coated haze particles.

At ambient temperature and pressure, particle droplet evaporation is almost completely prohibited by the coating, i.e., the particle maintains a constant size. With increased temperature the vapor pressure inside the droplet rises, the coating becomes partially permeable (it leaks), and the particle size decreases. This, then, accounts for the continuous drop in particle size and $b_{\text {scat }}$ inmmediately after heating starts (Fig. 4). Evidently, the coating is composed of nonvolatile matter (perhaps heavy organics) and its mass is conserved during heating. As a consequence, the thickness of the shrinking coating increases up to a point that it becomes "inelastic" and further deformation (shrinking) can only be accomplished by folding as shown in Fig. 10c.

\section{Discussion}

It has been demonstrated that simple thermal analyses of the Los Angeles aerosol can reveal some important information about its origin and its volatile fraction. The in situ quantitative characterization of 

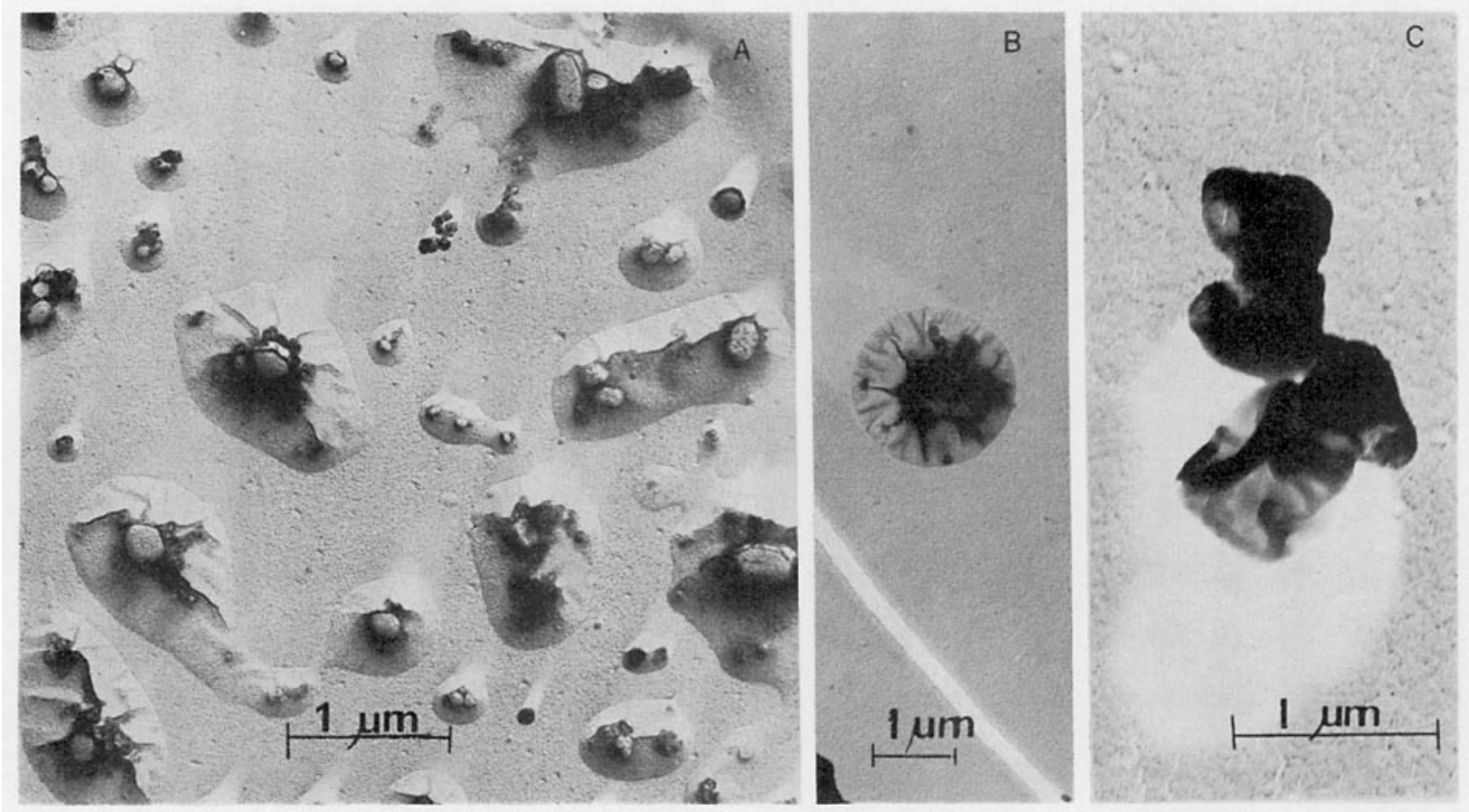

FIg. 10. Electron micrograph of unheated haze aerosol deposit. a) Most of the haze particle residues show wrinkles extending from the center outward. b) This picture gives direct evidence of droplet being coated by a nonvolatile layer that shrank and wrinkled after the volatile interior, probably water, evaporated in the vacuum chamber of the electron microscope. c) Electron micrograph of heated haze particle. It gives the appearance of an evacuated thick-walled rubber ball, supporting the evidence that the haze droplet was originally coated by a nonvolatile layer.

the volatile fraction is of importance because in the classical aerosol sampling techniques which involve aerosol deposition, many of the volatile components escape before analysis.

Pueshel $e t$ al. (1973) have suggested that the aerosol volatility could also be used to classify the origin of background aerosol and that thermo-nephelometric analyses should be incorporated into geophysical monitoring programs. Our results suggest that urban air pollution monitoring programs could also benefit from continuous thermal analyses. Recent experiments in the St. Louis Regional Air Pollution Study show that the major aerosol components of the St. Louis aerosol sulfuric acid and its salts (Charlson et al., 1974) can be successfully identified by thermal analyses.

As an extension of the present work, the frequency of occurrence of the "haze" and "smog" aerosol type in the Los Angeles basin would need to be assessed by year-round monitoring. Only a detailed study of the mechanism (s) by which coastal fog or cloud droplets may become stabilized and the determination of the chemical composition of the evaporation retardant coating can identify the cause of this inadvertent weather modification effect.

Acknowledgments. The authors thank S. K. Friedlander for his illuminating comments. This research was supported by the U. S. Environmental Protection
Agency, Division of Chemistry and Physics, Atmospheric Aerosol Research Section, under Grant 800308, and by the California Air Resources Board through contract to Rockwell International, Science Center.

\section{REFERENCES}

Ahlquist, N. C., and R. J. Charlson, 1967: A new instrument for evaluating the visual quality of air. J. Air Pollut. Control A ssoc., 17, 467-469.

Cadle, R. D., S. Rubin, C. L. Glassbrock and P. L. Magill, 1950: Identification of particles in Los Angeles smog by optical and electron microscopy. Arch. Ind. Hyg. Occup. Med., 2 , 698-715.

Charlson, R. J., A. H. Vanderpol, D. S. Covert, A. P. Waggoner and N. C. Ahlquist, 1974: Sulfuric acid ammonium sulfate aerosol: Optical detection in the St. Louis region. Science, $184,156$.

Commins, B. T., and P. J. Lawther, 1958: Volatility of 3,4-bensopyrene in relation to the collection of smoke samples. Brit. $J$. Cancer, 12, 351-354.

Dinger, J. E., H. B. Howell and T. A. Wojciechowski, 1970: On the source and composition of cloud nuclei in subsequent air mass over North Atlantic. J. Atmos. Sci., 27, 791-797.

Ensor, D. S., et al., 1972: Multiwavelength nephelometric measurements in the Los Angeles basin. J. Colloid Interface Sci. $39,242-248$.

Friedlander, S. K., 1973: Chemical element balances and identification of air pollution sources. Environ. Sci. Tech., 7, 235-240.

Gartrell, G., Jr., and S. K. Friedlander, 1975: Relating particulate poilution to sources: The 1972 aerosol characterization study. Atmos. Environ., 9, 279-299. 
Goetz, A., O. Preining and T. Kallai, 1961: The metastability of natural and urban aerosols. Geofis. Pura Appl., 50, 67-80.

Haagen-Smit, A., 1952: The chemistry and physiology of the Los Angeles smog. Ind. Eng. Chem., 44, 1342.

Heisler, S. L., S. K. Friedlander and R. B. Husar, 1973: The relationship of smog aerosol size and chemical composition to source characteristics. Aimos. Environ., 7, 633-649.

Hidy, G. M., Ed., 1972: Aerosols and Atmospheric Chemistry. Academic Press, 177 pp.

Husar, R. B., 1974: Recent developments in in situ measurement of submicron aerosols. Amer. Soc. Testing Mat. Spec. Tech. Publi., 157-192.

—, K. T. Whitby and B. Y. H. Liu, 1972 : Physical mechanisms governing the dynamics of Los Angeles aerosol. I. Colloid Interface Sci., 39, 211-224.

Mader, P. P. et al., 1954: Composition portion of atmospheric aerosols in the Los Angeles area. Ind. Eng. Chem., 44, 1352-1355.

Pueschel, R. F., B. A. Bodhaine and B. G. Mendonca, 1973: The proportion of volatile aerosols on the island of Hawaii. J. A ppl. Meteor., 12, 308-315.

Rubin, S., 1952: Liquid particles in atmospheric haze. J. Atmos. Terr. Phys., 2, 130-140.

Whitby, K. T., R. B. Husar and B. Y. H. Liu, 1972: The aerosol size distribution of the Los Angeles smog. J. Colloid. Interface Sci., 39, 177-204. 